\title{
Are preoperative histology and MRI useful for classification of endometrial cancer risk?
}

Noemie Body ${ }^{1}$, Vincent Lavoué ${ }^{1,5,6^{*}}$, Olivier De Kerdaniel ${ }^{1}$, Fabrice Foucher ${ }^{1,5}$, Sébastien Henno ${ }^{2}$, Aurélie Cauchois ${ }^{2}$, Bruno Laviolle ${ }^{3}$, Marc Leblanc ${ }^{4}$ and Jean Levêque ${ }^{1,5,6}$

\begin{abstract}
Background: The 2010 guidelines of the French National Cancer Institute (INCa) classify patients with endometrial cancer into three risk groups for lymph node invasion and recurrence on the basis of MRI and histological analysis of an endometrial specimen obtained preoperatively. The classification guides therapeutic choices, which may include pelvic and/or para-aortic lymphadenectomy. The purpose of this study was to evaluate the diagnostic performance of preoperative assessment to help identify intermediate- or high-risk patients requiring lymphadenectomy.
\end{abstract}

Methods: The study included all patients who underwent surgery for endometrial cancer between January 2010 and December 2013 at either Rennes University Hospital or Vannes Regional Hospital. The criteria for eligibility included a preoperative assessment with MRI and histological examination of an endometrial sample. A histological comparison was made between the preoperative and surgical specimens.

Results: Among the 91 patients who underwent a full preoperative assessment, the diagnosis of intermediate- or high-risk endometrial cancer was established by MRI and histology with a sensitivity of $70 \%$, specificity of $82 \%$, positive predictive value (PPV) of $87 \%$, negative predictive value (NPV) of $61 \%$, positive likelihood ratio (LR+) of 3.8 and negative likelihood ratio (LR-) of 0.3. The risk group was underestimated in $32 \%$ of patients and overestimated in $7 \%$ of patients. MRI underestimated endometrial cancer stage in $20 \%$ of cases, while endometrial sampling underestimated the histological type in $4 \%$ of cases and the grade in $9 \%$ of cases.

Conclusion: The preoperative assessment overestimated or underestimated the risk of recurrence in nearly $40 \%$ of cases, with errors in lesion type, grade or stage. Erroneous preoperative risk assessment leads to suboptimal initial surgical management of patients with endometrial cancer.

Keywords: Endometrial cancer, MRI, Endometrial sample, Risk group, Lymphadenectomy

\section{Background}

The FIGO (International Federation of Gynecology and Obstetrics) classification of endometrial cancer and its surgical management was reviewed in 2009-2010 [1]. The preoperative assessment recommended by the French National Cancer Institute (INCa) includes MRI and histological examination of an endometrial sample obtained by curettage with hysteroscopy or biopsy with a Cornier ${ }^{\circ}$ pipelle. The assessment determines the tumour stage,

\footnotetext{
* Correspondence: vincent.lavoue@chu-rennes.fr

'Gynaecology Department, Rennes University Hospital, Hôpital Sud, Rennes, France

${ }^{5}$ Oncogenesis, Stress and Signaling, ER 4440, CRCL CRLCC Eugène Marquis, Rennes, France

Full list of author information is available at the end of the article
}

histological type and grade for endometrioid (type I) adenocarcinomas [1]. The aim of the preoperative assessment is to classify patients into one of three risk groups (low, intermediate or high) for lymph node invasion and recurrence and to help guide surgical staging to determine whether pelvic and/or para-aortic lymphadenectomy should be performed [1-10]. Although no benefit for lymphadenectomy was seen in patients with early low-risk disease in two prospective randomised trials [11, 12], lymph node status is a strong prognostic factor for guiding the choice of adjuvant treatment $[9,13-18]$.

The preoperative evaluation of lymph node metastatic risk based on MRI is poor because used criteria are defective or incomplete [19-21]. For example, using MRI, 
myometrial involvement > $50 \%$ is underestimated in $21 \%$ and $32 \%$ of endometrioid grade 1 and grade 2 adenocarcinoma, respectively [22]. In the same way, the grade is underestimated by preoperative biopsy or curettage in 20 to $25 \%$ of preoperative endometrioid grade 1 adenocarcinoma [23]. Although this defective performance of each tool assessing preoperative risk, little data are available that evaluate combined MRI and preoperative biopsy to assess endometrial cancer risk for lymph node invasion and recurrence.

The aim of this study was to evaluate the combined performance of MRI and histological analysis in predicting the risk of lymph node invasion and recurrence. Used preoperatively, the combined assessment can identify which patients should undergo pelvic and/or para-aortic lymphadenectomy as per the existing guidelines [1].

\section{Methods}

\section{Design}

This is a retrospective study of all patients who underwent surgery for endometrial cancer between 1st January 2010 and 31st December 2013 at either Rennes University Hospital or Vannes Regional Hospital (by 5 general gynaecologic surgeons). The inclusion criterion was evidence of endometrial cancer of any type, grade or stage as confirmed by a preoperative endometrial sample or hysterectomy specimen. The exclusion criteria were lack of preoperative data concerning the type and grade (determined by endometrial sampling) or FIGO stage (determined by MRI). The research protocol was approved by the Institutional Review Board of the French College of Obstetrics and Gynaecology (CEROG 2014GYN-020).

\section{Data collection}

The following data were collected for all patients: patient characteristics (age, BMI, menopausal status, use of hormone replacement therapy for the menopause), surgical treatment (type of procedure, approach), adjuvant treatment, preoperative radiology and histology results, as well as final histology.

The preoperative MRI was performed following European Society of Urogenital Imaging guidelines [24]. The data required for FIGO 2009 staging (degree of myometrial, cervical, adnexal and serosal invasion, positive pelvic or para-aortic lymph nodes greater than $10 \mathrm{~mm}$ in size) were also collected. The data collected from the preoperative histology report were tumour type and grade for endometrioid tumours (type 1) and the method used: Cornier ${ }^{\circledR}$ pipelle (an outpatient procedure) or curettage with hysteroscopy (performed in the operating theatre). Following final analysis of the surgical specimen, the type, grade, presence of lymphovascular emboli and FIGO 2009 stage were recorded.

\section{Definition of risk levels for lymph node invasion}

Type 1 tumours consisted of endometrioid adenocarcinomas and mixed tumours with a mucinous or villoglandular component in addition to the endometrioid component. For these tumours, histological grade was defined by the percentage of the undifferentiated component: grade 1 corresponded to an undifferentiated component of less than $5 \%$, grade 2 from 6 to $50 \%$ and grade 3 more than $50 \%$. When nuclear atypia was marked, the grade was increased by 1 point [1].

Type 2 tumours were those with at least one serous, clear cell or carcinosarcoma component. Tumours that

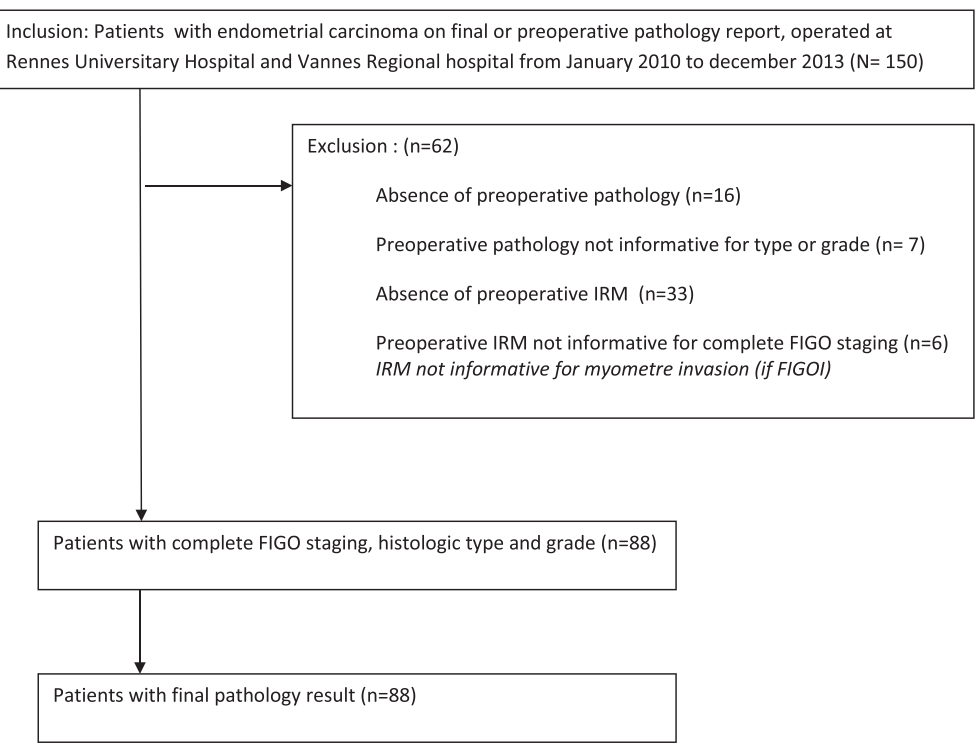

Fig. 1 Flow chart 
were completely undifferentiated or whose type could not be determined were classified as type 2 .

In both the preoperative and postoperative periods, on the basis of their FIGO 2009 stage, type and grade the tumours were classified into recurrence risk groups as defined in the European Society for Medical Oncology (ESMO) guidelines [5, 6]. The three risks groups were determined as follows: low risk - stage IA, grade 1 or 2 , histological type 1; intermediate risk - stage IA, grade 3 and stage $I B$, grade 1 or 2 , histological type 1 ; high risk - stage IB, grade 3 and, by extension, stage $\geq$ II, histological type 1 , as well as all type 2 tumours of any stage and tumours of any type or stage with lymphovascular emboli, as per French guidelines [1].

\section{Outcome measure}

The primary endpoint was the risk group (low, intermediate or high). Secondary endpoints were FIGO stage, myometrial, cervical and lymph node involvement as well as tumour type and grade.

\section{Statistical analysis}

The results of the preoperative assessment were compared with the final histological analysis of the surgical specimen. For type and grade assessment, the performance of the Cornier ${ }^{\circ}$ pipelle and curettage with hysteroscopy was compared.

The sensitivity, specificity, PPV, NPV, LR+ and LR- of the preoperative assessment were calculated for each endpoint, together with $95 \%$ confidence intervals (95\% CI). The percentage of underestimation or overestimation and accuracy rate were also calculated. The higher the LR+, the more useful the positive result of an examination proved to be. The examination was deemed useful when its $\mathrm{LR}+$ was greater than 5 . The closer the LR- was to 0 , the more useful the negative result of the examination proved to be [1].

The $\chi^{2}$ test or Fisher's exact test were used to compare categorical variables as appropriate. Results were considered significant when the $p$ value was less than 0.05 . All data were collected in an Excel database (Microsoft, Redmond, WA, USA) and analysed using R Core Team (2013) statistical software (R Foundation for Statistical Computing, Vienna, Austria; www.R-project.org).

\section{Results}

The study identified 150 patients who had undergone surgery for endometrial cancer between 2010 and 2013: $99(66.0 \%)$ at Rennes University Hospital and 51 (34.0 \%) at Vannes Regional Hospital.

Fifty-nine patients $(39.3 \%)$ were excluded for incomplete preoperative assessment data due to at least one of the following reasons: use of an imaging technique other than MRI (ultrasound, PET or CT scan) $(n=46)$, degree
Table 1 Characteristics of included patients $(n=91)$

\begin{tabular}{|c|c|}
\hline Variable & $n / \%$ \\
\hline Age $^{a}$ median and interval, in years & $67(38-90)$ \\
\hline $\mathrm{BMI}^{\mathrm{a}}$ median and interval in $\mathrm{kg} / \mathrm{m}^{2}$ & $29.96(19.23-53.83)$ \\
\hline Menopause $^{a}$ & $82(90.11 \%)$ \\
\hline Hormonal treatment for the menopause ${ }^{a}$ & $26(28.57 \%)$ \\
\hline \multicolumn{2}{|l|}{ Preoperative endometrial sample } \\
\hline Curettage & $44(48.35 \%)$ \\
\hline Pipelle & $47(51.64 \%)$ \\
\hline \multicolumn{2}{|l|}{ Surgery performed ${ }^{a}$} \\
\hline Total hysterectomy with BSO & $87(95.60 \%)$ \\
\hline Total hysterectomy & $4(4.40 \%)$ \\
\hline \multicolumn{2}{|l|}{ Surgical approach ${ }^{a}$} \\
\hline Laparotomy & $23(25.27 \%)$ \\
\hline Laparoscopy & $64(70.33 \%)$ \\
\hline Vaginal & $4(4.40 \%)$ \\
\hline \multicolumn{2}{|l|}{ Lymphadenectomy $^{\text {a }}$} \\
\hline No & $37(40.66 \%)$ \\
\hline Pelvic & $36(39.56 \%)$ \\
\hline Pelvic + sentinel lymph node & $3(3.30 \%)$ \\
\hline Pelvic + para-aortic & $13(14.29 \%)$ \\
\hline Sentinel lymph node & $2(2.20 \%)$ \\
\hline \multicolumn{2}{|l|}{ Final histology results ${ }^{a}$} \\
\hline \multicolumn{2}{|l|}{ FIGO stage $(2009)^{a}$} \\
\hline IA & $45(49.45 \%)$ \\
\hline $\mathrm{IB}$ & $21(23.08 \%)$ \\
\hline$\|$ & $13(14.29 \%)$ \\
\hline$\| \mathrm{A}$ & $2(2.20 \%)$ \\
\hline$\| \mathrm{BB}$ & $1(1.10 \%)$ \\
\hline\|\|$C$ & $7(7.69 \%)$ \\
\hline IV & $2(2.20 \%)$ \\
\hline \multicolumn{2}{|l|}{ Histological type ${ }^{a}$} \\
\hline Type 1 & $78(85.71 \%)$ \\
\hline Grade 1 & $46(50.55 \%)$ \\
\hline Grade 2 & $20(21.98 \%)$ \\
\hline Grade 3 & $12(13.19 \%)$ \\
\hline Type 2 & $11(12.09 \%)$ \\
\hline Absence of residual malignant cells & $2(2.20 \%)$ \\
\hline Lymphovascular embolia & $32(35.16 \%)$ \\
\hline \multicolumn{2}{|l|}{ Risk of recurrence $^{a}$} \\
\hline Low & $33(36.26 \%)$ \\
\hline Intermediate & $14(15.38 \%)$ \\
\hline High & 44 (48.35 \%) \\
\hline
\end{tabular}

BSO bilateral salpingo-oophorectomy

${ }^{a}$ There was no significant difference between the pipelle group and the curettage group 
of myometrial invasion not specified on the MRI and images not available for review $(n=7)$, chance discovery of cancer in the surgical specimen $(n=9)$, type or grade not specified on the preoperative histology report and slides not available for review $(n=11)$.

Ninety-one patients with endometrial cancer who had undergone a complete preoperative assessment (MRI to determine FIGO stage and histology to determine type and grade for type 1 tumours), were finally included in the study (Fig. 1).

The clinical and pathological characteristics of the patients are provided in Table 1.

\section{Histological analysis}

Table 2 compares the pre- and postoperative histological type.

Of 80 patients with type 1 cancer (endometrioid) preoperatively, 4 (5.0 \%) were reclassified as having type 2 cancer on final histological analysis. Conversely, of the 11 patients with type 2 cancer preoperatively, 4 (36.3 \%) were reclassified as having type 1 cancer on final histological analysis. For the diagnosis of type 2 tumours, regardless of the technique used the endometrial sample had sensitivity of $63.6 \%$ [95 \% CI 35.4-84.8], specificity of $95 \%$ [95\% CI 87.8-98.0], PPV of $63.6 \%$ [95 \% CI 35.4-84.8], NPV of $95 \%$ [ $95 \%$ CI of 87.8-98.0], LR+ of 12.7 [95 \% CI 4.436.5] and LR- of 0.4 [ $95 \%$ CI 0.1-0.8]. Regardless of the technique used, the endometrial sample correctly predicted

Table 2 Histological type of endometrial cancers: comparison of results of the preoperative and postoperative analyses $(n=91)$

\begin{tabular}{|c|c|c|c|c|c|}
\hline \multicolumn{2}{|c|}{$\begin{array}{l}\text { Preoperative } \\
\text { histological evaluation }\end{array}$} & \multirow{2}{*}{$\begin{array}{l}n \\
80\end{array}$} & \multicolumn{2}{|c|}{$\begin{array}{l}\text { Postoperative } \\
\text { histological result }\end{array}$} & \multirow{2}{*}{$\begin{array}{l}n(\%) \\
74(92.5 \%)\end{array}$} \\
\hline Type 1 & Endometrioid & & Type1 & Endometrioid & \\
\hline & Mucinous & & & & \\
\hline & Mixed endometrioid & & & Mucinous & \\
\hline & and mucinous & & & $\begin{array}{l}\text { Mixed } \\
\text { endometrioid } \\
\text { and mucinous }\end{array}$ & \\
\hline & & & Type 2 & $\begin{array}{l}\text { Mixed } \\
\text { endometrioid } \\
\text { and serous }\end{array}$ & $4(5.0 \%)$ \\
\hline & & & Other & $\begin{array}{l}\text { Absence of } \\
\text { residual } \\
\text { tumour }\end{array}$ & $1(1.25 \%)$ \\
\hline & & & & $\begin{array}{l}\text { Atypical } \\
\text { hyperplasia }\end{array}$ & $1(1.25 \%)$ \\
\hline \multirow[t]{3}{*}{ Type 2} & Serous & 11 & Type 1 & Endometrioid & $4(36.4 \%)$ \\
\hline & $\begin{array}{l}\text { Mixed endometrioid } \\
\text { and serous or clear } \\
\text { cells }\end{array}$ & & Type 2 & Serous & $7(63.6 \%)$ \\
\hline & Undifferentiated & & & $\begin{array}{l}\text { Mixed } \\
\text { endometrioid } \\
\text { and serous or } \\
\text { clear cells }\end{array}$ & \\
\hline
\end{tabular}

the histological type in $89.0 \%$ of cases, overestimated it in $6.6 \%$ of cases and underestimated it in $4.4 \%$ of cases (Table 3).

The endometrial sample was taken with a Cornier pipelle in 47 patients (51.6\%) and by curettage in 44 patients (48.3\%). Diagnostic performance for type 2 tumours is provided in Table 3. No significant difference was observed between the two techniques for diagnosis of histological type.

The diagnostic performance of grading was assessed in the 74 patients with a tumour diagnosed preoperatively as type 1 and confirmed postoperatively. Regarding endometrioid tumours, for the diagnosis of grade 3 tumours the endometrial sample had a sensitivity of $30.0 \%$ [95 \% CI 10.8-60.3], specificity of $98.4 \%$ [95 \% CI 91.7-99.7], PPV of 75.0 [95 \% CI 30.1-95.4], NPV of $90.0 \%$ [95 \% CI 80.8-95.1], LR+ of 19.2 [95 \% CI 2.2-166.9] and LR- of 0.7 [95 \% CI 0.4-1.1]. Endometrial sampling correctly predicted the grade for type 1 tumours in $89.2 \%$ of cases, overestimated it in $1.3 \%$ of cases, and underestimated it in $9.5 \%$ of cases (Table 4 ).

The performance of the pipelle and curettage for diagnosing grade 3 tumours among endometrioid tumours is provided in Table 4. There was no significant difference between the two sampling techniques for establishing the grade.

Lymphovascular emboli were found in 32 out of 91 patients $(35.3 \%)$ on histological analysis of the hysterectomy specimen. Emboli were detected in $20 \%$ of stage IA, $38 \%$ of stage IB, $38 \%$ of stage II, $80 \%$ of stage III and $100 \%$ of stage IV tumours regardless of type.

\section{MRI analysis}

The performance of the preoperative MRI for diagnosing lymph node, cervical and myometrial invasion is reported in Table 5. The degree of myometrial invasion was underestimated in $11.4 \%$ of cases, accurate in $81.8 \%$ of cases and overestimated in $6.8 \%$ of cases. Cervical invasion was underestimated in $10.9 \%$ of cases, accurate in $89.0 \%$ of cases and never overestimated. Fifty-two of the 91 patients (57.1 \%) underwent pelvic lymphadenectomy with paraaortic lymphadenectomy in 13 cases (14.3\%). Among these 52 patients, lymph node status was underestimated in $3.8 \%$ of cases, accurate in $78.8 \%$ of cases and overestimated in $17.3 \%$ of cases.

For the diagnosis of FIGO stages $>$ IA, MRI had a sensitivity of $78.3 \%$ [95 \% CI 64.4-87.7], specificity of $88.9 \%$ [95 \% CI 76.5-95.2], PPV of $87.8 \%$ [95 \% CI 74.5-94.7], NPV of $80.0 \%$ [95 \% CI 67.0-88.8], LR+ of 7.0 [95 \% CI 3.0-16.3] and LR- of 0.2 [95 \% CI 0.1-0.4] (Table 6).

For the diagnosis of FIGO stages $>$ IB, MRI had a sensitivity of $60.0 \%$ [95 \% CI 40.7-76.6], specificity of $93.9 \%$ [95 \% CI 85.4-97.6], PPV of 78.9 \% [95 \% CI 56.7-91.5], 
Table 3 Diagnosis of type 2 endometrial cancers by preoperative endometrial sample $(n=91)$

\begin{tabular}{llll}
\hline & Cornier ${ }^{\oplus}$ Pipelle $(n=47)$ & Curettage with hysteroscopy $(n=44)$ & Both types of sampling $(n=91)$ \\
\hline Sensitivity (\%) $[95 \% \mathrm{Cl}]$ & $60.0[23.1-88.2]$ & $66.7[30.0-90.3]$ & $63.6[35.4-84.8]$ \\
Specificity (\%) $[95 \% \mathrm{Cl}]$ & $97.6[87.7-99.6]$ & $92.1[79.2-97.3]$ & $95.0[87.8-98.0]$ \\
PPV (\%) $[95 \% \mathrm{Cl}]$ & $75.0[30.1-95.4]$ & $57.1[25.0-84.2]$ & $63.6[35.4-84.8]$ \\
NPV (\%) $[95 \% \mathrm{Cl}]$ & $95.3[84.5-98.7]$ & $94.6[82.3-98.5]$ & $95.0[87.8-98.0]$ \\
+LR [95 \% Cl] & $25.2[3.2-198.6]$ & $8.4[2.5-28.7]$ & $12.7[4.4-36.5]$ \\
-LR [95 \% Cl] & $0.4[0.14-1.2]$ & $0.4[0.1-1.1]$ & $0.4[0.1-0.8]$ \\
Overestimation (\%) & $2.1^{*}$ & $11.4^{*}$ & 6.6 \\
Accuracy rate (\%) & $93.6^{*}$ & $84.1^{*}$ & 89.0 \\
Underestimation (\%) & $4.3^{*}$ & $4.5^{*}$ & 4.4 \\
\hline
\end{tabular}

PPV positive predictive value, NPV negative predictive value, $+L R$ positive likelihood ratio, $-L R$ negative likelihood ratio

*There was no significant difference between the pipelle group and the curettage group $(p=0.259)$

NPV of $86.1 \%$ [95 \% CI 76.3-92.3], LR+ of 9.9 [95 \% CI 3.6-26.9] and LR- of 0.4 [95\% CI 0.2-0.6].

FIGO stages IA, IB, II, III and IV considered individually were underestimated in $20.9 \%$ of cases, accurate in $65.9 \%$ of cases and overestimated in $13.2 \%$ of cases (Fig. 2).

\section{Performance of the preoperative assessment for determining risk}

For diagnosing intermediate- or high-risk endometrial cancer, the preoperative combination of MRI and histology had a sensitivity of $70.0 \%$ [95 \% CI 58.0-80.8], specificity of $81.8 \%$ [95\% CI 65.6-91.4], PPV of $87.2 \%$ [95 \% CI 74.8-94.0], NPV of $61.4 \%$ [95 \% CI 46.6-74.3], LR+ of 3.8 [95 \% CI 1.8-8.2] and LR- of 0.3 [95 \% CI 0.2-0.5] (Table 6).

Considered independently, the risk groups (low, intermediate and high) were underestimated in $31.9 \%$ of cases, accurate in $60.4 \%$ of cases and overestimated in $7.7 \%$ of cases.

In practice, if we consider only the 23 patients who were in the low- or intermediate-risk group preoperatively but reclassified as high risk on final histology, the error was due to grade underestimation in 3 cases (14.2\%), underestimation of FIGO stage in 9 cases $(42.8 \%)$ and presence of emboli in 11 cases (47.8\%).

Among the 37 patients with type 1 , grade $1-2$, stage IA adenocarcinoma on final analysis, 6 (16.2 \%) were classified in the high-risk group owing to the presence of emboli. Similarly, among the 22 patients with type 1 grade 3 stage IA adenocarcinoma or grade 1-2 stage IB adenocarcinoma, 8 (36.4 \%) were classified in the highrisk group due to the presence of emboli (Fig. 3).

\section{Surgical management according to risk group}

In terms of surgical management, pelvic lymphadenectomy was not performed despite being considered in $6 \mathrm{pa}-$ tients classified in the intermediate- rather than low-risk group. Thirteen patients underwent pelvic lymphadenectomy only despite para-aortic lymphadenectomy also being recommended following final analysis. Ten patients did not undergo lymphadenectomy despite pelvic lymphadenectomy being recommended. Among these 23 patients, only 2 underwent a new procedure (one patient in the intermediate-risk group and one in the high-risk group) involving pelvic lymphadenectomy. No tumour invasion was observed in either case.

Table 4 Diagnosis of grade 3 endometrial cancers, among endometrioid-type cancers, by preoperative endometrial sample $(n=74)$

\begin{tabular}{llll}
\hline & Cornier ${ }^{\oplus}$ Pipelle $(n=41)$ & Curettage with hysteroscopy $(n=33)$ & Both types of sampling $(n=74)$ \\
\hline Sensitivity (\%) $[95 \% \mathrm{Cl}]$ & $28.6[8.2-64.1]$ & $33.3[6.1-79.2]$ & $30.0[10.8-60.3]$ \\
Specificity (\%) $[95 \% \mathrm{Cl}]$ & $97.1[85.1-99.5]$ & $100[88.6-100]$ & $98.4[91.7-99.7]$ \\
PPV (\%) $[95 \% \mathrm{Cl}]$ & $66.7[20.8-93.9]$ & $100[20.7-100]$ & $75.0[30.1-95.4]$ \\
$\mathrm{NPV}(\%)[95 \% \mathrm{Cl}]$ & $86.8[72.7-94.2]$ & $93.7[79.9-98.3]$ & $90.0[80.8-95.1]$ \\
+LR [95\% Cl] & $9.7[1.0-92.9]$ & $\mathrm{NA}$ & $19.2[2.2-166.9]$ \\
-LR [95 \% Cl] & $0.7[0.5-1.2]$ & $\mathrm{NA}$ & $0.7[0.4-1.1]$ \\
Overestimation (\%) & $2.4^{*}$ & $0.0^{*}$ & 1.3 \\
Accuracy rate (\%) & $85.4^{*}$ & $93.9^{*}$ & 89.2 \\
Underestimation (\%) & $12.2^{*}$ & $6.1^{*}$ & 9.5
\end{tabular}

PPV positive predictive value, NPV negative predictive value, $+L R$ positive likelihood ratio, $-L R$ negative likelihood ratio, $N A$ not applicable

*There was no significant difference between the pipelle group and the curettage group $(p=0.555)$ 
Table 5 Diagnosis of deepness invasion of endometrial cancers by preoperative MRI $(n=91)$

\begin{tabular}{llll}
\hline & Cervical invasion $(n=91)$ & Myometrial invasion $\geq 50 \%(n=91)$ & Lymph node invasion $(n=52)$ \\
\hline Sensitivity (\%) $[95 \% \mathrm{Cl}]$ & $23.1[8.2-50.3]$ & $73.7[58.0-85.0]$ & $71.4[35.9-91.8]$ \\
Specificity (\%) $[95 \% \mathrm{Cl}]$ & $100[95.3-100]$ & $88.0[76.2-94.4]$ & $80.0[66.2-89.1]$ \\
PPV (\%) $[95 \% \mathrm{Cl}]$ & $100[43.8-100]$ & $82.4[66.5-91.7]$ & $35.7[16.3-61.2]$ \\
NPV (\%) $[95 \% \mathrm{Cl}]$ & $88.6[80.3-93.7]$ & $81.5[69.2-89.6]$ & $94.7[82.7-98.5]$ \\
+LR [95 \% Cl] & $\mathrm{NA}$ & $6.1[2.8-13.3]$ & $3.6[1.7-7.6]$ \\
-LR [95\% Cl] & $\mathrm{NA}$ & $0.3[0.2-0.5]$ & $0.4[0.1-1.6]$ \\
Overestimation (\%) & 0 & 6.8 & 17.3 \\
Accuracy rate (\%) & 89.1 & 81.8 & 78.8 \\
Underestimation (\%) & 10.9 & 11.4 & 3.8 \\
\hline
\end{tabular}

PPV positive predictive value, NPV negative predictive value, $+L R$ positive likelihood ratio, $-L R$ negative likelihood ratio, $N A$ not applicable

\section{Discussion}

Our study showed that MRI underestimated the stage of endometrial cancer in $20 \%$ of cases, and that endometrial sampling underestimated the type and grade in $4 \%$ and $9 \%$ of cases respectively. The combination of these two preoperative investigations does not compensate for any underestimation that may occur at an individual level. The risk group for lymph node invasion was underestimated in $31.9 \%$ of patients, leading to surgical understaging with incomplete or no lymphadenectomy performed in $30.7 \%$ of patients treated for endometrial cancer.

The limitations of our study are those inherent to its retrospective design: loss of data and selection bias. Interobserver variability in MRI and histology slide analysis can impair diagnostic performance. However our results are consistent with the literature [9, 25]. Several authors have studied the correlation between preoperative and final histology [9, 22, 25-32]. In terms of determining the tumour type, these studies report an accuracy rate of $74 \%$ to $92 \%[9,28]$, with no significant difference between the different sampling techniques, a finding comparable to our own results. In terms of determining the grade, these studies report an accuracy rate of $44 \%$ to $94 \%[9,22,25,28,29]$, with no significant difference between the different sampling techniques either, a finding comparable to our own results $[22,25,26,28,29]$. Similarly, numerous authors have addressed the diagnostic performance of MRI for evaluating the degree of myometrial, cervical and nodal invasion [21,33-37]. The results of our study are comparable to those in the literature $[9,25,29,37-42]$ which reports an accuracy rate of between $66 \%$ and $90 \%$ and a positive likelihood ratio $>5$ for evaluation of the degree of myometrial invasion [1]. Few studies have specifically evaluated the performance of MRI for FIGO staging, which is a composite criterion [9, 40, 42]. Raimond et al. [9] reported a modest performance with MRI for determining FIGO stage and a $30 \%$ underestimation rate, consistent with the $20 \%$ underestimation rate observed in our study. Their findings are similar to those of our study and confirm that the preoperative assessment performs better for more advanced and therefore higher risk stages. When predicting FIGO stage, overestimation by MRI is only $13 \%$ in both our studies.

The concept of risk groups was introduced after 2000 $[2,5,6,13,14,43,44]$ to estimate the risk of lymph node invasion and, over the longer term, recurrence, in early stage disease. The study by Bendifallah et al. [2] analysed the usefulness of different risk-group stratification models and concluded that none of the models was ideal for predicting recurrence and lymph node invasion.

Table 6 Diagnosis of intermediate- and/or high-risk endometrial cancers by preoperative assessment (MRI and endometrial sample) $(n=91)$

\begin{tabular}{|c|c|c|c|c|c|}
\hline & \multicolumn{2}{|c|}{ Endometrial sample } & \multirow{2}{*}{$\begin{array}{l}\text { MRI } \\
\text { FIGO Stage }>\text { IA }\end{array}$} & \multicolumn{2}{|c|}{ Combination (MRI and histology) } \\
\hline & Type 2 & Grade 3 & & High risk & Intermediate and high risk \\
\hline Sensitivity (\%) [95 \% Cl] & $63.6[35.4-84.8]$ & $30.0[10.8-60.3]$ & $78.3[64.4-87.7]$ & $47.7[33.8-62.1]$ & $70.0[58.0-80.8]$ \\
\hline Specificity (\%) $[95 \%$ Cl] & $95.0[87.8-98.0]$ & $98.4[91.7-99.7]$ & $88.9[76.5-95.2]$ & $93.6[82.8-97.8]$ & $81.8[65.6-91.4]$ \\
\hline PPV (\%) $[95 \%$ Cl] & $63.6[35.4-84.8]$ & $75.0[30.1-95.4]$ & $87.8[74.5-94.7]$ & $87.5[69.0-95.7]$ & $87.2[74.8-94.0]$ \\
\hline NPV (\%) $[95 \%$ Cl] & $95.0[87.8-98.0]$ & $90.0[80.8-95.1]$ & $80.0[67.0-88.8]$ & $65.7[53.7-75.9]$ & $61.4[46.6-74.3]$ \\
\hline$+\operatorname{LR}[95 \% \mathrm{Cl}]$ & $12.7[4.4-36.5]$ & $19.2[2.2-166.9]$ & $7.0[3.0-16.3]$ & $7.5[2.4-23.3]$ & $3.8[1.8-8.2]$ \\
\hline -LR $[95 \% \mathrm{Cl}]$ & $0.4[0.1-0.8]$ & $0.7[0.4-1.1]$ & $0.2[0.1-0.4]$ & $0.6[0.4-0.7]$ & $0.3[0.2-0.5]$ \\
\hline
\end{tabular}

$P P V$ positive predictive value, $N P V$ negative predictive value, $+L R$ positive likelihood ratio, $-L R$ negative likelihood ratio 


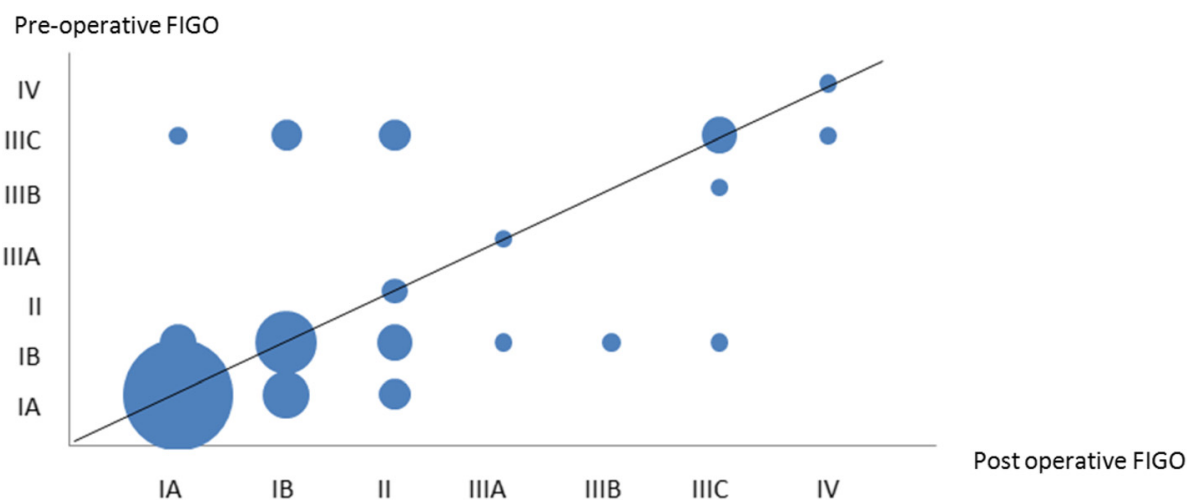

Fig. 2 Pre and post operative assessment of FIGO stage. For the diagnosis of FIGO stages $>$ IB, MRI had a sensitivity of $60.0 \%[95 \% \mathrm{Cl}$ 40.7-76.6], specificity of $93.9 \%$ [95 \% Cl 85.4-97.6], Positive Predictive Value of $78.9 \%$ [95 \% Cl 56.7-91.5], Negative Predictive Value of $86.1 \%[95 \% \mathrm{Cl} 76.3-92.3]$

However risk stratification is still used to guide surgical management, and in particular the decision on whether or not to perform pelvic and/or para-aortic lymphadenectomy during total hysterectomy with bilateral salpingo-oophorectomy. Several stratification systems have been proposed, based on proven risk factors such as type, grade and stage, but also age and presence of lymphovascular emboli [2-7, 31, 45-48]. The latter criterion is an independent prognostic factor correlated with the risk of lymph node involvement and survival $[31,43,46,49,50]$. The 5 -year overall survival rate for patients with emboli, of any stage, is $64 \%$ as compared to $88 \%$ for patients without emboli $[5,6]$. Lymphovascular emboli should be considered in the risk prediction process to guide endometrial cancer management decisions. The inclusion of lymphovascular emboli in the risk prediction equation was responsible for half the cases of underestimation in our study - a finding consistent with the literature [51]. The underestimation is completely understandable given that emboli were found in $35 \%$ of cases on final histological analysis of the surgical specimen and that they are undetected by preoperative histology. As shown by Hirschowitz et al., emboli are visible in the myometrium surrounding the tumour area but not in the tumour itself where tissue retraction is a source of confusion [31]. There has been no study on the possibility of detecting emboli preoperatively to date.

Our study and a previous one [2] show that the different models for stratification into risk groups for lymph node invasion are not useful for preoperative classification of patients. Lymphadenectomy is therefore not performed at the time of hysterectomy for $30 \%$ of patients with endometrial cancer. The risk of overestimating the risk, i.e. performing an unnecessary lymphadenectomy, is low (estimated at $13 \%$ in our series in agreement with the literature). Even if a preoperative assessment consisting of

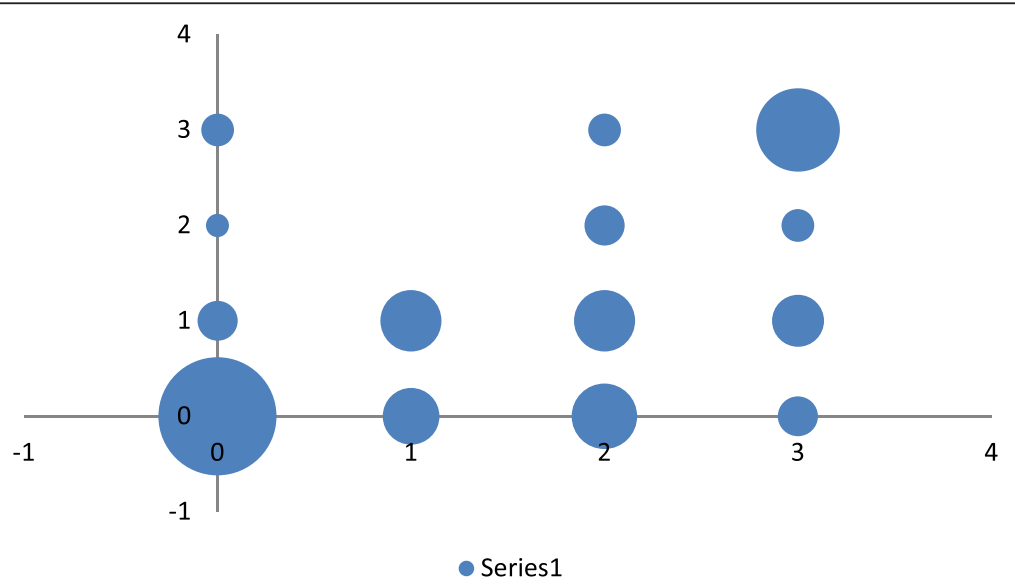

Fig. 3 Pre and post operative assessment of risk. For diagnosing intermediate- or high-risk endometrial cancer, the preoperative combination of MRI and histology had a sensitivity of $70.0 \%$ [95 \% Cl 58.0-80.8], specificity of $81.8 \%$ [95 \% Cl 65.6-91.4], Predictive Positive Value of 87.2 \% [95 \% Cl 74.8-94.0], Negative Predictive Value of 61.4\% [95 \% Cl 46.6-74.3]. 0 low risk, 1: intermediate risk, 2: high risk, 3 very high risk 
MRI and histology is not useful for estimating the risk of lymph node invasion, histological evaluation of lymph nodes is still considered desirable for patients with endometrial cancer who are classified as low-risk. To limit the morbidity associated with routine lymphadenectomy in patients with low-risk endometrial cancer, the sentinel lymph node technique may offer a useful alternative.

\section{Conclusion}

The ESMO and of INCa guidelines propose therapeutic de-escalation for the management of endometrial cancer. Lymphadenectomy is not offered for low-risk endometrial cancer $[1,5,6,9]$. However in patients with endometrial cancer classified as low-risk, risk stratification errors are observed on preoperative assessment, with underestimation occurring in at least $30 \%$ of patients. Conversely, preoperative risk overestimation is low. In conclusion, in patients with endometrial cancer classified as low-risk as determined by a preoperative assessment consisting of MRI and endometrial sampling, histological examination of lymph nodes still proves useful. The sentinel lymph node technique could be used to limit the morbidity associated with routine lymphadenectomy and could be used routinely in patients with preoperative low risk endometrial cancer because of poor performance of preoperative assessment of combined MRI and endometrial sampling [21, 41, 52-60].

\section{Acknowledgements}

VL is supported by "la Vannetaise" (2014). We are grateful to Tracey Westcott for editorial assistance.

\section{Funding}

This study was supported by funds from Teaching Hospital of Rennes.

\section{Availability of data and materials}

The data used is stored in the clinical trials office at Teaching hospital of Rennes, France. Any request of data and material may be sent to the corresponding author.

\section{Authors' contributions}

NB contributed to the conception and design, data collection, analysis and interpretation, manuscript drafting, revising, and approval for publishing; VL contributed to the conception and design, data collection, analysis and interpretation, manuscript drafting, revising, and approval for publishing; ODK contributed to the conception and design, data collection, analysis and interpretation, manuscript drafting, revising, and approval for publishing; FF contributed to the data analysis and interpretation; manuscript drafting and revising; $\mathrm{SH}$ contributed to the tissue procurement, data collection and manuscript approval for publishing; AC contributed to the data collection and manuscript approval; BL contributed to the data collection and manuscript approval; ML contributed to the data collection and manuscript approval; and JL contributed to the conception and design, data collection, analysis and interpretation, manuscript drafting, revising, and approval for publishing. All authors have read and approved the manuscript.

\section{Competing interests}

The authors declare that they have no competing interests.

\section{Ethics approval and consent to participate}

This study was approved by the Institutional Review Board of the French College of Obstetrics and Gynaecology (CEROG 2014-GYN-020). Informed consent from the patients was obtained.

\section{Author details}

'Gynaecology Department, Rennes University Hospital, Hôpital Sud, Rennes, France. ${ }^{2}$ Pathology Department, CHU Pontchaillou, Rennes University Hospital, Rennes, France. ${ }^{3}$ Clinical Pharmacology Department, Rennes University Hospital, CIC Inserm 0203, Hôpital Pontchaillou, Rennes, France. ${ }^{4}$ Gynaecology Department, Bretagne Atlantique Hospital, Vannes, France. ${ }^{5}$ Oncogenesis, Stress and Signaling, ER 4440, CRCL CRLCC Eugène Marquis, Rennes, France. ${ }^{6}$ University of Rennes 1, Faculty of Medicine, Rennes, France.

Received: 2 February 2016 Accepted: 13 July 2016

Published online: 19 July 2016

\section{References}

1. INCa. Cancer de l'endomètre, Boulogne-Billancourt edn: Institut National du cancer; 2010.

2. Bendifallah S, Canlorbe G, Collinet P, Arsene E, Huguet F, Coutant C, et al. Just how accurate are the major risk stratification systems for early-stage endometrial cancer? Br J Cancer. 2015;112(5):793-801.

3. Burke WM, Orr J, Leitao M, Salom E, Gehrig P, Olawaiye AB,B, et al. Endometrial cancer: a review and current management strategies: part II. Gynecol Oncol. 2014;134(2):393-402.

4. Burke WM, Orr J, Leitao M, Salom E, Gehrig P, Olawaiye AB, et al. Endometrial cancer: a review and current management strategies: part I. Gynecol Oncol. 2014;134(2):385-92.

5. Colombo N, Preti E, Landoni F, Carinelli S, Colombo A, Marini C, et al. Endometrial cancer: ESMO clinical practice guidelines for diagnosis, treatment and follow-up. Ann Oncol. 2011;22 Suppl 6:vi35-9.

6. Colombo N, Preti E, Landoni F, Carinelli S, Colombo A, Marini C, Colombo N, Preti E, Landoni F, Carinelli S, Colombo A, Marini C, et al. Endometrial cancer: ESMO clinical practice guidelines for diagnosis, treatment and follow-up. Ann Oncol. 2013;24 Suppl 6:vi33-8.

7. Creasman WT, Odicino F, Maisonneuve P, Beller U, Benedet JL, Heintz AP, et al. Carcinoma of the corpus uteri. Int J Gynaecol Obstet. 2003;83 Suppl 1:79-118.

8. Kitchener $\mathrm{HC}$, Trimble EL. Endometrial cancer state of the science meeting. Int J Gynecol Cancer. 2009;19(1):134-40.

9. Raimond E, Canlorbe G, Bendifallah S, Hudry D, Selvi F, Ballester M, et al. [Endometrial carcinoma. Application of the guidelines of 2010: multicentre trial]. Bull Cancer. 2014;10(7-8):703-13.

10. Werner HM, Trovik J, Marcickiewicz J, Tingulstad S, Staff AC, Amant F, et al. Revision of FIGO surgical staging in 2009 for endometrial cancer validates to improve risk stratification. Gynecol Oncol. 2012:125(1):103-8.

11. Benedetti Panici P, Basile S, Maneschi F, Alberto Lissoni A, Signorelli M, Scambia G, et al. Systematic pelvic lymphadenectomy vs. no lymphadenectomy in early-stage endometrial carcinoma: randomized clinical trial. J Natl Cancer Inst. 2008;100(23):1707-16.

12. Kitchener H, Swart AM, Qian Q, Amos C, Parmar MK. Efficacy of systematic pelvic lymphadenectomy in endometrial cancer (MRC ASTEC trial): a randomised study. Lancet. 2009;373(9658):125-36.

13. Keys HM, Roberts JA, Brunetto VL, Zaino RJ, Spirtos NM, Bloss JD, et al. A phase III trial of surgery with or without adjunctive external pelvic radiation therapy in intermediate risk endometrial adenocarcinoma: a Gynecologic Oncology Group study. Gynecol Oncol. 2004;92(3):744-51.

14. Creutzberg CL, van Putten WL, Koper PC, Lybeert ML, Jobsen JJ, WarlamRodenhuis CC, et al. Surgery and postoperative radiotherapy versus surgery alone for patients with stage-1 endometrial carcinoma: multicentre randomised trial. PORTEC Study Group. Post Operative Radiation Therapy in Endometrial Carcinoma. Lancet. 2000;355(9213):1404-11.

15. Jutzi L, Hoskins P, Lim P, Aquino-Parsons C, Tinker A, Kwon JS. The importance of adjuvant chemotherapy and pelvic radiotherapy in high-risk early stage endometrial carcinoma. Gynecol Oncol. 2013;131(3):581-5.

16. Kupets R, Le T, Bentley J, Farrell S, Fortier MP, Giede C, et al. The role of adjuvant therapy in endometrial cancer. J Obstet Gynaecol Can. 2013;35(4):375-9.

17. Foerster R, Kluck R, Rief H, Rieken S, Debus J, Lindel K. Survival of women with clear cell and papillary serous endometrial cancer after adjuvant radiotherapy. Radiat Oncol. 2014;9:141. 
18. Landrum LM, Nugent EK, Zuna RE, Syzek E, Mannel RS, Moore KN, et al. Phase II trial of vaginal cuff brachytherapy followed by chemotherapy in early stage endometrial cancer patients with high-intermediate risk factors. Gynecol Oncol. 2014;132(1):50-4.

19. Kakhki VR, Shahriari S, Treglia G, Hasanzadeh M, Zakavi SR, Yousefi Z, et al. Diagnostic performance of fluorine 18 fluorodeoxyglucose positron emission tomography imaging for detection of primary lesion and staging of endometrial cancer patients: systematic review and meta-analysis of the literature. Int J Gynecol Cancer. 2013;23(9):1536-43.

20. Sawicki W, Spiewankiewicz B, Stelmachow J, Cendrowski K. The value of ultrasonography in preoperative assessment of selected prognostic factors in endometrial cancer. Eur J Gynaecol Oncol. 2003;24(3-4):293-8.

21. Selman TJ, Mann CH, Zamora J, Khan KS. A systematic review of tests for lymph node status in primary endometrial cancer. BMC Womens Health. 2008;8:8.

22. Frumovitz M, Singh DK, Meyer L, Smith DH, Wertheim I, Resnik E, et al. Predictors of final histology in patients with endometrial cancer. Gynecol Oncol. 2004;95(3):463-8.

23. Neubauer NL, Havrilesky LJ, Calingaert B, Bulusu A, Bernardini MQ, Fleming ND, et al. The role of lymphadenectomy in the management of preoperative grade 1 endometrial carcinoma. Gynecol Oncol. 2009;112(3):511-6.

24. Kinkel K, Forstner R, Danza FM, Oleaga L, Cunha TM, Bergman A, et al. Staging of endometrial cancer with MRI: guidelines of the European Society of Urogenital Imaging. Eur Radiol. 2009;19(7):1565-74.

25. Groff B, Pouget O, Stoll F, Mathelin C, Baldauf JJ, Akladios CY. [Pertinence of the preoperative exploration in the evaluation of the risk of lymph node metastasis in endometrial cancer]. Gynecol Obstet Fertil. 2014;42(2):92-6.

26. Dijkhuizen FP, Mol BW, Brolmann HA, Heintz AP. The accuracy of endometrial sampling in the diagnosis of patients with endometrial carcinoma and hyperplasia: a meta-analysis. Cancer. 2000;89(8):1765-72.

27. Elsandabesee D, Greenwood P. The performance of Pipelle endometrial sampling in a dedicated postmenopausal bleeding clinic. J Obstet Gynaecol. 2005;25(1):32-4.

28. Huang GS, Gebb JS, Einstein MH, Shahabi S, Novetsky AP, Goldberg GL. Accuracy of preoperative endometrial sampling for the detection of high-grade endometrial tumors. Am J Obstet Gynecol. 2007;196(3):243. e241-245

29. Ortoft G, Dueholm M, Mathiesen O, Hansen ES, Lundorf E, Moller C, et al. Preoperative staging of endometrial cancer using TVS, MRI, and hysteroscopy. Acta Obstet Gynecol Scand. 2013;92(5):536-45.

30. Traen K, Holund B, Mogensen O. Accuracy of preoperative tumor grade and intraoperative gross examination of myometrial invasion in patients with endometrial cancer. Acta Obstet Gynecol Scand. 2007;86(6):739-41.

31. Hirschowitz L, Nucci M, Zaino RJ. Problematic issues in the staging of endometrial, cervical and vulval carcinomas. Histopathology. 2013;62(1):176-202.

32. Sany O, Singh K, Jha S. Correlation between preoperative endometrial sampling and final endometrial cancer histology. Eur J Gynaecol Oncol. 2012;33(2):142-4.

33. Manfredi R, Mirk P, Maresca G, Margariti PA, Testa A, Zannoni GF, et al. Local-regional staging of endometrial carcinoma: role of MR imaging in surgical planning. Radiology. 2004;231(2):372-8.

34. Rieck GC, Bulman J, Whitaker R, Leeson SC. A retrospective review of magnetic resonance imaging in assessing the extent of myometrial infiltration for patients with endometrial carcinoma. J Obstet Gynaecol. 2005;25(8):765-8.

35. Sala E, Crawford R, Senior E, Shaw A, Simcock B, Vrotsou K, et al. Added value of dynamic contrast-enhanced magnetic resonance imaging in predicting advanced stage disease in patients with endometrial carcinoma. Int J Gynecol Cancer. 2009;19(1):141-6.

36. Taieb S, Ceugnart L, Leblanc E, Chevalier A, Cabaret V, Querleu D. [MR imaging of endometrial carcinoma: role and limits]. Bull Cancer. 2002;89(11):963-8

37. Taieb S, Rocourt N, Narducci F, Ceugnart L. [Endometrial cancer imaging]. Bull Cancer. 2012;99(1):13-20.

38. Antonsen $\mathrm{SL}$, Jensen LN, Loft $\mathrm{A}$, Berthelsen AK, Costa J, Tabor $\mathrm{A}$, et al. $M R I, P E T / C T$ and ultrasound in the preoperative staging of endometrial cancer - a multicenter prospective comparative study. Gynecol Oncol. 2013;128(2):300-8

39. Saarelainen SK, Koobi L, Jarvenpaa R, Laurila M, Maenpaa JU. The preoperative assessment of deep myometrial invasion by three-dimensional ultrasound versus MRI in endometrial carcinoma. Acta Obstet Gynecol Scand. 2012;91(8):983-90.

40. Zamani F, Goodarzi S, Hallaji F, Zamiri A, Deilami T, Malek M, et al. Diagnostic value of pelvic MRI for assessment of the depth of myometrial invasion and cervical involvement in endometrial cancer: comparison of new versus Old FIGO staging. Iran J Radiol.

2012;9(4):202-8

41. Ballester M, Koskas M, Coutant C, Chereau E, Seror J, Rouzier R, et al. Does the use of the 2009 FIGO classification of endometrial cancer impact on indications of the sentinel node biopsy? BMC Cancer. 2010;10:465.

42. Beddy P, O'Neill AC, Yamamoto AK, Addley HC, Reinhold C, Sala E. FIGO staging system for endometrial cancer: added benefits of MR imaging. Radiographics. 2012;32(1):241-54.

43. Bendifallah S, Canlorbe G, Arsene E, Collinet P, Huguet F, Coutant C, et al. French multicenter study evaluating the risk of lymph node metastases in early-stage endometrial cancer: contribution of a risk scoring system. Ann Surg Oncol. 2015

44. Todo $Y$, Kato H, Kaneuchi M, Watari H, Takeda M, Sakuragi N. Survival effect of para-aortic lymphadenectomy in endometrial cancer (SEPAL study): a retrospective cohort analysis. Lancet. 2010;375(9721):1165-72.

45. Bendifallah S, Canlorbe G, Raimond E, Hudry D, Coutant C, Graesslin O, et al. External validation of nomograms designed to predict lymphatic dissemination in patients with early-stage endometrioid endometrial cancer: a multicenter study. Am J Obstet Gynecol. 2015;212:56. e51-57.

46. Koskas M, Bassot K, Graesslin O, Aristizabal P, Barranger E, Clavel-Chapelon F, et al. Impact of lymphovascular space invasion on a nomogram for predicting lymph node metastasis in endometrial cancer. Gynecol Oncol. 2013;129(2):292-7.

47. Pecorelli S. Revised FIGO staging for carcinoma of the vulva, cervix, and endometrium. Int J Gynaecol Obstet. 2009;105(2):103-4.

48. Werner HM, Trovik J, Marcickiewicz J, Tingulstad S, Staff AC, Engh ME, et al. A discordant histological risk classification in preoperative and operative biopsy in endometrial cancer is reflected in metastatic risk and prognosis. Eur J Cancer. 2013:49(3):625-32.

49. van der Putten $\amalg$, Geels YP, Ezendam NP, van der Putten HW, Snijders MP, van de Poll-Franse LV, et al. Lymphovascular space invasion and the treatment of stage I endometrioid endometrial cancer. Int J Gynecol Cancer. 2015;25(1):75-80.

50. Solmaz U, Mat E, Dereli M, Turan V, Gungorduk K, Hasdemir P, et al. Lymphovascular space invasion and cervical stromal invasion are independent risk factors for nodal metastasis in endometrioid endometrial cancer. Aust N Z J Obstet Gynaecol. 2015;55(1):81-6.

51. Brun $\mathrm{L}$, Ouldamer L, Bourdel N, Huchon C, Koskas M, Gauthier T. Management of stage I endometrial cancer in France: a survey on current practice. Ann Surg Oncol. 2015

52. Ballester M, Dubernard G, Lecuru F, Heitz D, Mathevet $P$, Marret $H$, et al. Detection rate and diagnostic accuracy of sentinel-node biopsy in early stage endometrial cancer: a prospective multicentre study (SENTI-ENDO). Lancet Oncol. 2011;12(5):469-76.

53. Ballester M, Naoura I, Chereau E, Seror J, Bats AS, Bricou A, et al. Sentinel node biopsy upstages patients with presumed low- and intermediate-risk endometrial cancer: results of a multicenter study. Ann Surg Oncol. 2013;20(2):407-12

54. Darai E, Zacharopoulou C, Touboul C, Chereau E, Ballester M. [Sentinel node procedure and endometrial cancer: senti-endo results]. Bull Cancer. 2012;99(1):35-41.

55. Kang S, Yoo HJ, Hwang JH, Lim MC, Seo SS, Park SY. Sentinel lymph node biopsy in endometrial cancer: meta-analysis of 26 studies. Gynecol Oncol. 2011;123(3):522-7.

56. Koskas M, Chereau E, Ballester M, Dubernard G, Lecuru F, Heitz D, et al. Accuracy of a nomogram for prediction of lymph-node metastasis detected with conventional histopathology and ultrastaging in endometrial cancer. Br J Cancer. 2013;108(6):1267-72

57. Naoura I, Canlorbe G, Bendifallah S, Ballester M, Darai E. Relevance of sentinel lymph node procedure for patients with high-risk endometrial cancer. Gynecol Oncol. 2015;136(1):60-4.

58. Plante M, Touhami O, Trinh XB, Renaud MC, Sebastianelli A, Grondin K, Gregoire J. Sentinel node mapping with indocyanine green and endoscopic near-infrared fluorescence imaging in endometrial cancer. A pilot study and review of the literature. Gynecol Oncol. 2015;137(3):443-7. 
59. Raimond E, Ballester M, Hudry D, Bendifallah S, Darai E, Graesslin O, et al. Impact of sentinel lymph node biopsy on the therapeutic management of early-stage endometrial cancer: results of a retrospective multicenter study. Gynecol Oncol. 2014;133(3):506-11.

60. Touhami O, Trinh XB, Gregoire J, Sebastianelli A, Renaud MC, Grondin K, et al. Predictors of non-sentinel lymph node (non-SLN) metastasis in patients with sentinel lymph node (SLN) metastasis in endometrial cancer. Gynecol Oncol. 2015.

Submit your next manuscript to BioMed Central and we will help you at every step:

- We accept pre-submission inquiries

- Our selector tool helps you to find the most relevant journal

- We provide round the clock customer support

- Convenient online submission

- Thorough peer review

- Inclusion in PubMed and all major indexing services

- Maximum visibility for your research

Submit your manuscript at www.biomedcentral.com/submit 